\title{
Use of Concept Maps to Assess Secondary School Chemistry Investigative Practical Work
}

\author{
Dr. Monica Gakii Ituma \\ Lecturer, School of Education, Chuka University, P.O Box 59296- 00100, Nairobi. Kenya
}

\begin{abstract}
This paper presents simple ways in which concept maps can be used to assess meaningful learning in chemistry practical work for secondary school learners. The study was carried out using design research based study materials developed to facilitate secondary school investigative practical work in chemistry. The concept maps were used to assess learners understanding of concepts and skills learnt during the laboratory practical work. Chemistry learners at Form One level of secondary school in Kenya were involved in laboratory practical work using design based research materials for learner investigative practical work. After the practical sessions, an evaluation of students' skill and concept understanding was done by use of two separate concept maps. The first concept map was to assist the learner articulate the understanding of concepts acquired during the lessons while the second concept map guided the learner to demonstrate the basic process skills acquired. A total of sixty (60) concept maps were analyzed. The results obtained indicated positive learner's concept understanding as well as the effectiveness of the instructional materials in used. The learners were of the view that the concept maps helped them identify connections between learnt concepts.
\end{abstract}

Keywords: Concept mapping, practical work assessment, chemistry assessment, investigative practical DOI: $10.7176 / \mathrm{JEP} / 10-18-19$

Publication date:June $30^{\text {th }} 2019$

\section{Introduction}

Chemistry teaching all levels involves use of a lot of practical. At secondary school level in Kenya, practical work involves learners carrying out well outlined activities in a cookbook style. The relationship between the activities and concepts intended to be learnt is however low (Ituma, 2015). In order to make learning meaningful in the laboratories, it is important that learners are able to establish relations between theory and practice as well as with their everyday experiences (Safdar, et al 2013). It is of vital importance to link the concepts learnt with the activities carried out in the laboratory. Concept maps are useful in providing these important links thus turning the focus of learning and assessment of chemistry from rote learning to meaningful learning. This is because well-structured concept maps are able to show highly integrated knowledge structures that are important in facilitating cognitive activities and skills such as problem solving (Kilic \& Cakmak, 2013).

It is also of importance to note that in Kenya chemistry practical work is tested by use of both theory and practical paper. Practical tests are usually not done at lower levels of secondary school chemistry learning (that is in Form 1 and 2). Direct testing of practical work through practical test papers are done at higher levels of chemistry in Form 3 and Form 4. The use of concept maps as suggested in this study could be of importance in testing conceptualization and understanding of skills gained during practical work at all levels including at the lower secondary school chemistry.

Investigative practical work in the laboratory itself requires much concentration. (Kilic \& Cakmak, 2013) argues that the laboratories are complex information rich environments in which the students may become overwhelmed in their efforts to process the information effectively. This commonly leads to lack of connection between concept areas. Pareek, (2015) indicates that students frequently lack the ability to associate their laboratory experience with the important chemical concepts. Studies have shown that on the use of concept maps could be immensely useful in focusing learner attention on the concepts and improve their understanding of procedures used in laboratory practical work (Pareek, 2015; Safdar et al, 2013; Ozmen, Demircioğlu \& Coll, 2009)

Concept maps were used as an evaluation tool gauge students' concept understanding and skill development. Form 1 learners involved in the study did not have much experience with construction and use of concept maps and could have found it difficult to develop the maps without guidance. They were therefore provided with structured guide of fill-in concept maps which they filled in information on their understanding of the concepts and observations. The concept maps were simple and easy for the learner easy to use and for the teacher to mark and grade.

\section{The Use of Concept Maps}

Concept maps are commonly used in the teaching and assessing of chemistry. A concept map is a graphical tool that organizes, connects, and synthesizes information. Concept maps show concepts in circles or boxes (nodes) and one can indicate relationships between concepts by use of connecting lines and linking words. The label on 
the line is an explanation that indicates how the two concepts are related. The combination of two nodes and a labelled line is referred to as proposition which is the basic unit of meaning used to judge the relationship between concepts (Ruiz-Primo, 2004). Concept mapping is a technique used to show relationship between interrelated concepts placed in a hierarchy, linked by lines labelled with connecting words expressing propositions linking the concepts (Ruiz-Primo, 2004; Aksela, 2005). They are used to organize information in order to bring about meaningful learning. Concept maps can be used as a tool of learning, a teaching tool, curriculum development, lesson planning method or as a method of evaluating of students' understanding (Aksela, 2005; Kilic \& Cakmak, 2013).

Assessment of laboratory work by direct use of concept mapping is not a common practice in Kenya. During laboratory work, students carry out activities producing a set of results which are not commonly related back the conceptual framework that underpins the experimental work in a meaningful way (Safdar et al, 2013) Meaningful learning takes place when learners are able to recognise interrelationships between different segments of the concepts and being able to join the segments and create meaning (Ruiz-Primo, 2004; Ituma, 2015). The commonly used chemistry assessment methods which are mainly multiple choice and short answer questions are good in testing concepts but have no ability of showing learner understanding of relationships or even broader applications of the concepts (Soika \& Reiska, 2014). Concept maps are better in reflecting differences among students' knowledge. Ruíz-Primo (2000), however notes that concept interrelatedness is an essential property of knowledge, and one aspect of competence in a domain is well structured knowledge. Expertise in the use of concept maps both in learning and assessment should be developed from an early level of science learning.

Some educators have indicated concern over the use of concept maps in assessing chemistry learning due to challenges in interpreting results and lack of standardization of scoring methods (Ruiz-Primo, 2004). Klassen (2006). It is however important to note that there are varied concept map task constraints with various degrees of directness that can be used in assessment of learners' conceptualization of chemistry content. These range from very high directed techniques which are fill-in maps with fill-in nodes or lines to, construction of maps where concepts are provided and structure suggested, to constructing maps where only concepts are provided to constructing maps where no concepts are provided (Ruíz-Primo, 2004). In this study, this challenge of evaluating the results of concept maps was overcome by using structured concept maps with high degree of directness where learners only filled the missing concepts. In this case the response format is direct where learners fill in the blanks and their responses are marked as correct or incorrect.

As the learners progress they are expected to construct their own concept maps with lower degrees of directness which would reflect their knowledge structure more directly. The scoring of such concept maps is more complex. According to Kiliç \& Çakmak (2013), scoring of a concept map is based on several criteria such as: i) Validity of propositions and relationships connecting the concepts, ii) Number of hierarchical levels and correctness of the hierarchical level, iii) Number of cross-links and the validity of cross links, iv) Number of links and extent of latitudinal and longitudinal branching, v) Number of examples and vi) Appropriateness of general and specific examples. Reiska, Cañas, Novak, \& Miller (2008) suggested a similar scoring criteria which include: 1) recognition and use of concepts; 2) presence of linking phrases; 3) degree of ramification; 4) hierarchical depth, and 5) presence of cross-links.

\section{Methodology}

\subsection{Research Method}

Design-Based Research (DBR) design was employed in the development of instructional materials for chemistry investigative practical work that were used by the learners in carrying out laboratory activities for this study. Design-Based Research (DBR) is a flexible methodology aimed at improving educational practices through iterative analysis, design, development, and implementation, based on collaboration among researchers and practitioners in real-world settings, and leading to contextually-sensitive design principles and theories (Wang \& Hannafin, 2005; DBRC, 2003). The study was carried out in five phases which are (1) Assessment of the practices and needs of Chemistry practical work in schools (2) Design and development of Chemistry practical work instructional materials prototype (3) Try out of the prototypes (4) Evaluation of the instructional strategies (5) Refinement of the materials (Ituma, 2015). During the evaluation phase, structured concept maps were used as one of the tools. Learners carried out Activities for the six practical lessons on the topic of acids, bases and indicators. The activities were based on the objectives of the local secondary school chemistry syllabus the process also adapted a lot from available materials by changing the practical activities into investigative practical work problems to encourage learner-centred classroom practice through presenting scenarios and asking students to develop experimental plans to solve the problems (Ituma \& Twoli, 2015).

Fill-in concept mapping was used where the teacher constructs a concept map and then removes the concept labels and allows learners to fill them. The learners therefore, use critical thinking skills along with problem solving skills (Kilic \& Cakmak, 2013). The fill-in spaces could be provided at the nodes (concepts) or at the lines 
linking the concepts (propositions). A study by Ruíz-Primo, (2000) showed that the scores of students were not affected by the use of either fill-in the node or fill-in the linking line used. It was however noted that fill-in-thenode maps were easier for students than fill-in-the-linking line maps. For this particular study the learners were provided with fill-in nodes only. This was in consideration that it was their first concept map to use in chemistry laboratory work.

Two separate concept maps were used, one concept map guided by a structure as shown in Figure 1 was used to indicate understanding of concepts acquired during the practical lessons.

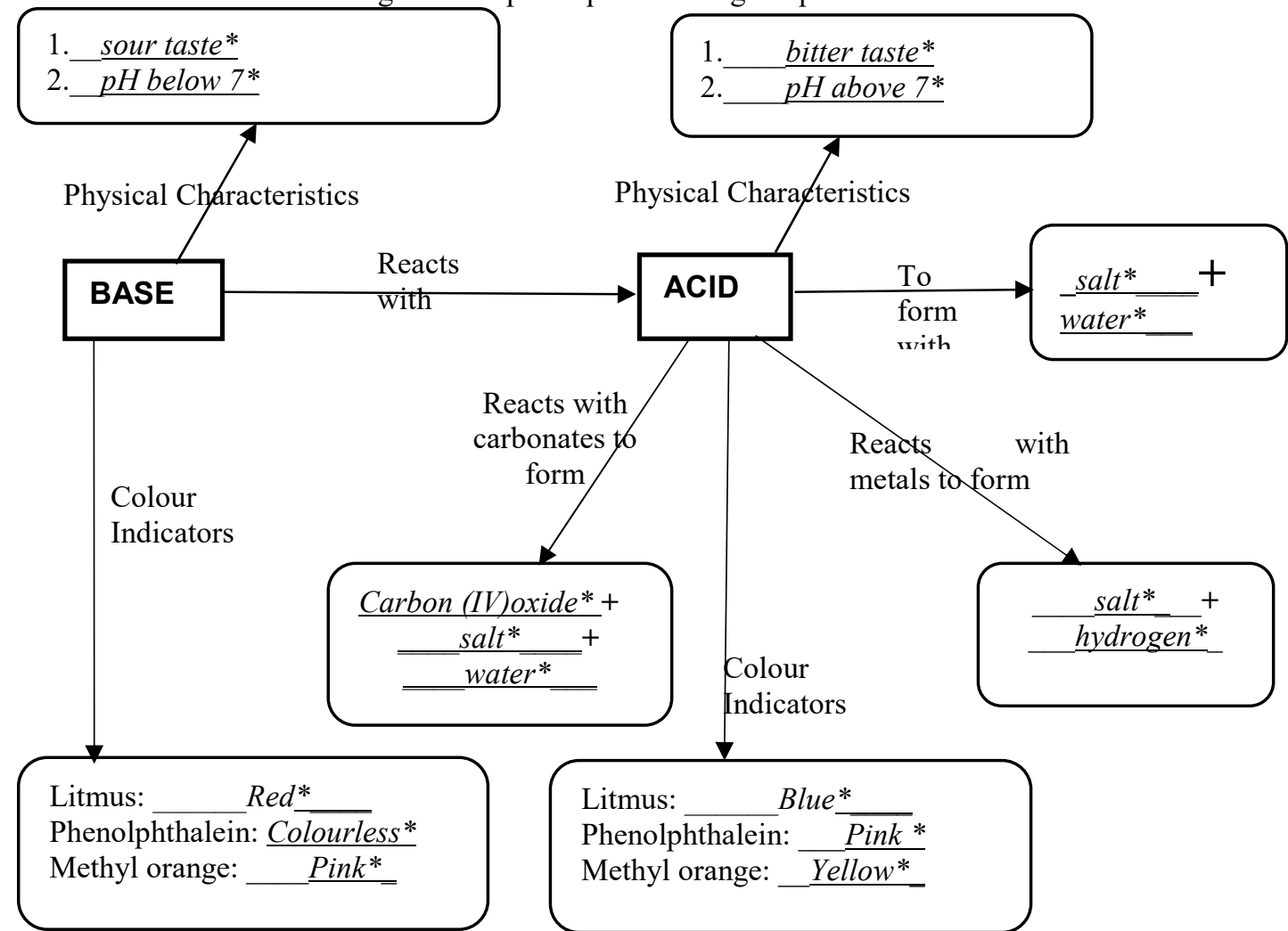

Figure 1: Concept map demonstrating understanding of concepts on acids and bases

*Areas left unfilled for the learners to fill

The lines marked with a *were filled by the students. In the figure shown however, the expected answer is filled in italics. This map tested conceptual understanding of the basic characteristics of acids and bases.

The second concept map guided by the structure on Figure 2 was used to help the learner demonstrate the understanding of skills acquired during the learning. 


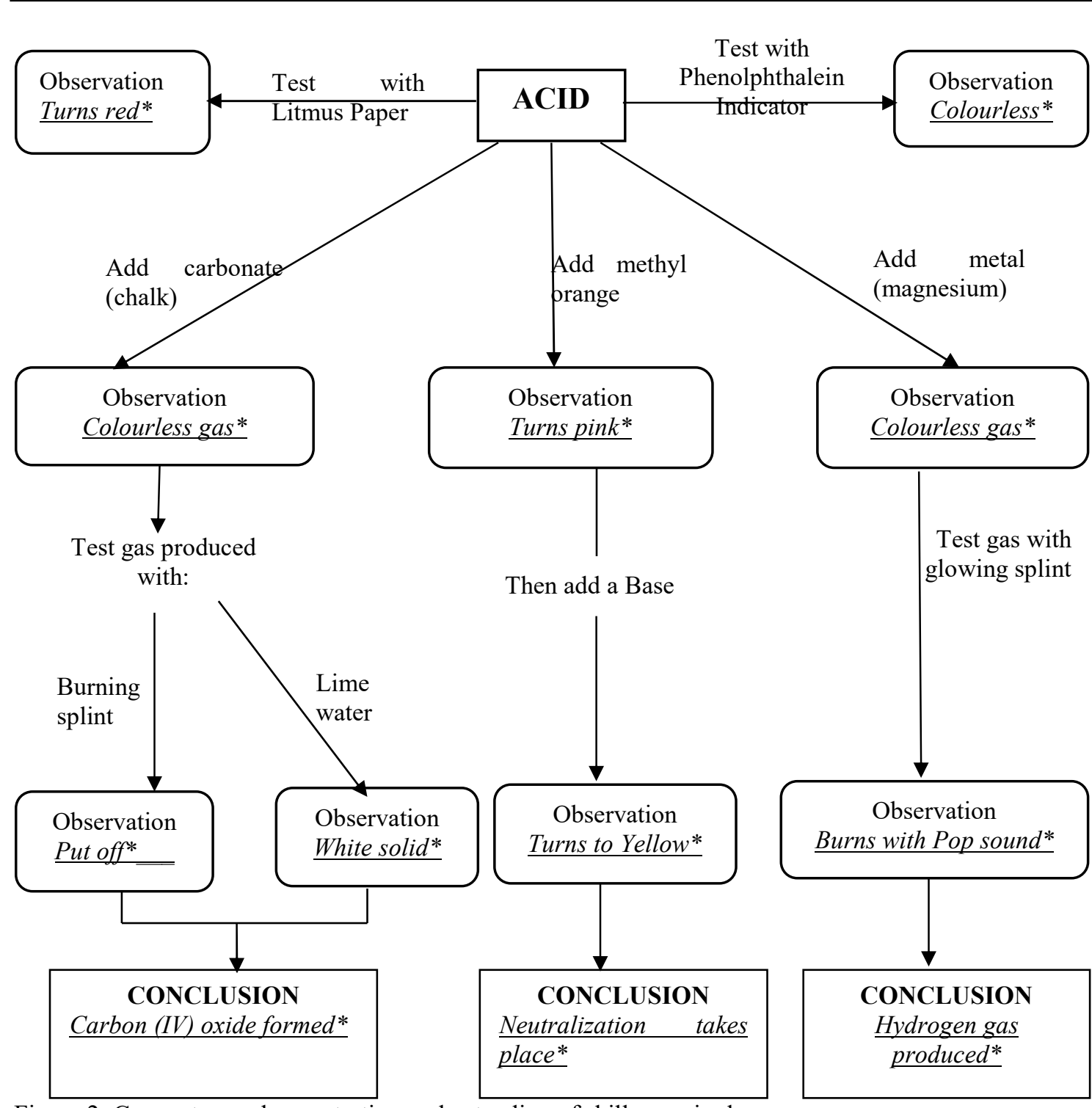

Figure 2: Concept map demonstrating understanding of skills acquired

* Areas left unfilled for the learners to fill

The key skills gained that this level of learning are manipulative skills, ability to carry out observation and making inferences from observations made.

\subsection{Construction of the concept maps}

In order to construct appropriate concept maps, the researcher first determined the knowledge and skills that learners would have acquired from the activities carried out. This was also related to the objectives of the syllabus used for form one learners in the topic. The steps used for constructing concept maps were as suggested by Kiliç \& Çakmak, (2013) which include: i) Defining the focus concept ii) Indetifying key concepts iii) ranking the concepts iv) adding more specific concepts and doing hierarchical arrangement of concepts and v) Labeling the lines with action or linking words. They also noted that specific examples of concepts can be added below the concept labels. These steps were used to develop the two concept maps.

The focus concept for the first concept map shown in Figure 1 was; The characteristics of acid and base. The key concepts identified were;

- Physical characteristics of acids and bases (taste and $\mathrm{pH}$ value)

- Products of reaction of acid with a base, carbonates and metals.

- Colour of various indicators (litmus indicator, phenolphthalein indicator and methyl orange indicator) in acidic and in basic solutions.

For the second concept map shown in Figure 2, the focus concept was: Observations and activities related to reactions of acids. The following key concepts were identified;

- Testing with acid/base indictors (litmus indicator, phenolphthalein indicator and methyl orange 


\section{indicator)}

- Reaction with carbonates (chalk)

- $\quad$ Reaction with metals (magnesium)

- Reaction with base (anti-acid tablet)

- Testing of the gas produced when acid reacts with carbonate and when acid reacts with metal

- Inferencing or making conclusions on observations made

\subsection{Implementation of the Study and Data Collection}

A sample of 60 learners were involved in the study. Learners were exposed to six laboratory lessons using design based materials for investigative practical work. After the practical lessons, learners were provided with the two fill-in concept maps shown in Figure 1 and Figure 2 to help them summarize results of their practical activities and assess their conceptualization of concepts and skills learnt during the practical work. Each learner filled both concept maps. These were collected, marked and scored by the researcher. The filled in information was marked as simply correct or incorrect since the concept maps were highly directed with simple concepts to fill in the provided spaces. The marks were converted to percentages and their means calculated. Using a semi-structured post laboratory interview for the learners who participated in the study. The interview was to gather their views on the usefulness of the concept maps in assessing and guiding their learning.

\section{Results}

A total of 60 concept maps was analyzed. Learner responses were graded in percentage and their means were calculated. The results from the concept map on the concepts (from Figure 1) produced a mean of $89.8 \%$ while that of skills understanding (Figure 2) produced a mean of $71.3 \%$. These results were considered to indicate the effectiveness of the instructional materials in learning. These high mean values of performance were taken to be an indicator of the effectiveness of instructional materials in improving conceptualization of content mater and developing basic observational skills. It also indicates that learners were able to make connections between concepts, activities carried out observations, and inferences.

The learners' perceptions on the use of concept maps as assessment tools collected through a semistructured interview was that the concept maps challenged them into thinking through the process and activities carried out during practical work. They were also of the view that they were going to use the concept maps as a revision tool because it provided a comprehensive summary of the investigative practical activities they had carried out.

\section{Conclusion}

Concept maps can form a strong tool of evaluating chemistry practical work at all levels of learning. Though the study focused on simple structured concept maps, learners could be slowly weaned into more complex concept maps and eventually be allowed to construct their own concept maps after conducting practical laboratory activities. Using the ideas generated from the concept maps, students can be trained to construct concept maps. Just like Ruíz-Primo (2004) suggests, that this can be done in a short period of time with little practice. Concept maps can be structured in different ways. After the assessment they can be used in revision of concepts. They can also be revised and concepts added. Kiliç, M., \& Çakmak, M. (2013) noted that good concept maps usually result from several revisions. As emphasis in learner-based laboratory investigations in developing countries is increasing, there is need to invest more time and resources in defining laboratory activities that provide linkages in concepts that can be assessed through concept mapping and defining the types of concept maps appropriate at different levels of chemistry learning.

\section{References}

Aksela, M. (2005). Supporting meaningful chemistry learning and higher-order thinking through computerassisted inquiry: A Design Research Approach. Thesis, University of Helsinki; Finland. Retrieved from http://ethesis.helsinki.fi,/julkaisut/mat/kemia

DBRC. (2003). Design-Based Research Collective, Design-Based Research: An Emerging Paradigm for Educational Inquiry. Educational Researcher. 32. (1) 5-8.

Ituma, M.G.(2015). Developing instructional materials that address challenges facing teachers in secondary school chemistry investigative practical work; A case of Kajiado County, Kenya. Unpublished Ph.D thesis. Nairobi. Kenyatta university, Kenya.

Ituma, M.G., \& Twoli N.W. (2015). Developing an instructional model to support teaching of investigative practical work in secondary school chemistry. International Journal of Scientific Research and Innovative Technology. $\quad 2$ (9) 31-34. ISSN: 2313-3759. Available: http://www.ijsrit.com/uploaded_all_files/2301450447_h5.pdf

Kiliç, M., \& Çakmak, M. (2013). Concept maps as a tool for meaningful learning and teaching in chemistry 
education. International Journal on New Trends in Education and Their Implications. 4(4), 14. ISSN 13096249

Ozmen, H., Demircioğlu, G. \& Coll, R. K.( 2009). A comparative study of the effects of a concept mapping enhanced laboratory experience on Turkish high school students' understanding of acid-base chemistry. International Journal of Science and Mathematics Education, 7(1), 1-24.

Pareek, R. B. (2015). Concept Maps in Organic Chemistry Practicals. World Journal of Chemical Education 3(1): 22-26.

Reiska, P., Cañas, A. J., Novak, J. D., \& Miller, N. L. (2008). Concept mapping for meaningful learning and assessment. The need for a paradigm shift in science education for post-soviet societies. Frankfurt: Peter Lang Company.

Ruíz-Primo, M. (2000). On the use of concept maps as an assessment tool in science: What we have learned so far. Revista Electrónica de Investigación Educativa, 2 (1). Retrieved from: http://redie.uabc.mx/vol2nol/contents-ruizpri.html

Ruiz-Primo, M. A. (2004). Examining concept maps as an assessment tool. In Concept maps: Theory, methodology, technology. Proceedings of the First International Conference on Concept Mapping. Pampolonia, Spain: Universidad Publica de Navarra. Retrieved from: http://cmc.ihmc.us/papers/cmc2004036.pdf

Safdar M.S., Hussain. A., Shah, I.S, \& Tasnim M.H. (2013). Make the laboratory work meaningful through Concept maps and V Diagram IOSR Journal of Research \& Method in Education (IOSR-JRME). 3(2), 5560. e-ISSN: 2320-7388, p-ISSN: 2320-737X Available: www.iosrjournals.org

Safdar, M. (2010). A comparative study of Ausubelian and Traditional methods of teaching physics at secondary school level in Pakistan. Unpublished Ph.D thesis. Islamabad. National University of Modern Languages, Islamabad.

Soika, K., Reiska, P. (2014). Using concept mapping for assessment in science education. Journal of Baltic Science Education. 13(5). ISSN 1648-3898

Stensvold M. \& J. T. Wilson, 1992, Using concept maps as a tool to apply chemistry concepts to laboratory activities. Journal of Chemical Education, 69(3), 230-232

Wang, F., \& Hannafin, M. J. (2005). Design-based research and technology: Enhanced learning environments. Educational Technology Research and Development, 53(4), 5-23.

\footnotetext{
Author

Dr. Ituma Monica is lecturer of Science Education (Chemistry) and an Education Consultant with Knowledge Resource Centre (East Africa) Ltd. She earned a Master in science Education in 2012 and a Ph.D. in science education (Chemistry) in 2015 from Kenyatta University, Nairobi, Kenya. She has wide experience in teaching chemistry and physics at secondary school level in Kenya. She currently teaches Science Education and Educational Communication Technology. She is passionate about Science Education, improving teaching strategies, developing learner-centred science teaching materials and developing appropriate science assessment techniques.
} 